\title{
Quality of Care in Patients with Type 1 Diabetes During the COVID-19 Pandemic: A Cohort Study from Southern Brazil
}

Luciana Foppa ( $\sim$ Ifoppa@hcpa.edu.br)

Hospital de Clínicas de Porto Alegre https://orcid.org/0000-0002-2371-2217

Janine Alessi

Universidade Federal do Rio Grande do Sul

Betina Nemetz

Universidade Federal do Rio Grande do Sul

Rosimeri de Matos

Hospital São Lucas da PUCRS: Hospital Sao Lucas da PUCRS

\section{Gabriela Heiden Telo}

Pontifícia Universidade Católica do Rio Grande do Sul: Pontificia Universidade Catolica do Rio Grande do Sul

\section{Beatriz D. Schaan}

Hospital de Clinicas de Porto Alegre

\section{Research Article}

Keywords: Diabetes mellitus, Type 1, Quality indicators, Health care, COVID-19, Ambulatory care.

Posted Date: January 20th, 2022

DOI: https://doi.org/10.21203/rs.3.rs-1259052/v1

License: (c) (1) This work is licensed under a Creative Commons Attribution 4.0 International License.

Read Full License 


\section{Abstract}

Background: Optimal glycemic control is the main goal for patients with diabetes. The results of type 1 diabetes patients' neglected demands during the pandemic can determine a long-term negative clinical, social, and economic impact, and result in worse diabetes control and a higher incidence of chronic complications. Therefore, this study aims to evaluate the impact of the COVID-19 outbreak in the quality of care of patients with type 1 diabetes in Southern Brazil.

Methods: Cohort study based on electronic medical records of patients with type 1 diabetes, with scheduled appointments between January $1^{\text {st }} 2020$, and November $6^{\text {th }} 2020$, at a university public hospital. The quality indicators used were: assessment of albuminuria and/or serum creatinine, lipid profile, thyroid-stimulating hormone, glycated hemoglobin, retinopathy, and neuropathy. McNemar test was used to analyze categorical variables and the Wilcoxon test for continuous variables.

Results: Out of 289 patients, $49.5 \%$ were women aged $40 \pm 12$ years old. During the pandemic, 252 patients had at least one face-to-face appointment canceled. The quality of care indicators showed a significant worsening during the COVID-19 pandemic compared to the previous year $(p<0.001)$. In 2019 , $23.2 \%$ of the participants had all the indicators evaluated, while in 2020 , during the pandemic, only $3.5 \%$ had all of them evaluated.

Conclusion: The COVID-19 pandemic hindered the offer of comprehensive and quality care to patients with type 1 diabetes.

\section{Introduction}

The incidence of type 1 diabetes mellitus is progressively increasing worldwide. In Brazil, there are near 51.5 million cases of type 1 diabetes in adolescents aged under 14 years, being the third country in absolute numbers of cases in the world [1]. Optimal glycemic control is the main goal for these patients, as it is associated with less acute and chronic diabetic complications [2, 3]. However, some challenges emerge, including the need for patient compliance with treatment, frequent blood glucose monitoring, attention to diet and physical activity and the risk of suffering from adverse treatment effects, especially hypoglycemia [4]. As a result, many subjects with type 1 diabetes fail to achieve optimal therapeutic targets $[5,6]$. Goals setting can be useful to standardize the management of these patients and to provide multidisciplinary comprehensive care [7]. These goals may have a great impact in quality of care improvement, and also cover the clinical domains of diagnostics, monitoring, treatment and complications screening in individuals with type 1 diabetes. [8, 9].

Coronavirus disease 2019 (COVID-19) - a disease caused by the SARS-CoV-2 started in 2019 in Wuhan, China - was declared by the World Health Organization (WHO) as a public health emergency of international concern on January 30th, 2020 [10]. In Brazil, although the first case of COVID-19 was confirmed on February 26, 2020, by July 2021 the mark of 19 million cases and 550 thousand deaths was surpassed, being considered one of the epicenters of the world pandemic [11, 12]. The social 
distancing measures affected the lifestyle of the population, brought changes in daily habits and health consequences, especially to people with type 1 diabetes $[13,14]$. The practice of physical activities and the eating habits have been modified during the pandemic, affecting the control of the disease and may even worsen glycemic control $[15,16]$. Moreover, the cancellation of medical appointments and the difficulty to obtain medicines and medical prescriptions may become a challenge to control this disease during the pandemic. These factors may negatively affect the quality of care for patients with type 1 diabetes, who may lose their routine monitoring and screening during the pandemic, possibly resulting in worse long-term outcomes.

Studies carried out to the date show that the COVID-19 pandemic and the social distancing measures have significantly reduced the results of the follow-up, control, screening, and vaccination indicators for diabetes patients in primary care centers $[17,18]$. The pandemic has been increasing the prevalence of emotional stress, eating disorders, and sleep disorders of patients with type 1 and type 2 diabetes mellitus $[14,19]$. However, no study performed to date has assessed how the current situation affects the quality of care for patients with type 1 diabetes, who need regular monitoring in specialized centers. During the pandemic, the results of these patients' neglected demands can determine a long-term negative clinical, social, and economic impact, and result in worse diabetes control and a higher incidence of chronic complications. This study aims to evaluate the impact of the COVID-19 outbreak in the quality of care of patients with type 1 diabetes mellitus in Southern Brazil, according to the indicators proposed by guidelines.

\section{Methods}

\section{Study Design and Setting}

This is a cohort study of subjects with type 1 diabetes from Southern Brazil, with data collected retrospectively from medical records. Participants with a previous diagnosis of type 1 diabetes, with regular follow-up at the endocrinology outpatient clinic of a tertiary care public hospital in Southern Brazil were selected by requesting a query in electronic medical records with keywords, identifying all patients with type 1 diabetes mellitus treated in the institution. Electronic medical records were used to select participants who met the inclusion criteria for the study. Scheduled appointments between January 1st and November 6th, 2020, were used to assess the impact of the pandemic on quality of care indicators in this population, in comparison with the data collected from the same group of patients in 2019. In Brazil, the first case of COVID-19 was diagnosed on February 26th, 2020 [11], and, during the pandemic, three main peaks occurred in the months of August 2020, December 2020 and March 2021 in the South region [20]. In March 22nd, 2020, the city of Porto Alegre, where most studied participants reside, presented its first requirement that guides social distancing and regulates establishments. Despite flexibility of social restrictions at some points, the social distancing for high risk groups for severe COVID-19, such as diabetic patients, remained very prevalent throughout 2020 [21]. 


\section{Participants}

All patients aged over 18 years diagnosed with type 1 diabetes mellitus, who received outpatient care between January 2019 and November 2020 in our institution, were potentially eligible. For inclusion in the study, these patients should have at least one appointment scheduled between January and December 2020, regardless of whether this medical appointment was attended or not. Exclusion criteria were having a record of other type of diabetes - type 2 diabetes, MODY, LADA or uncertain type of diabetes -, pregnancy, death, outpatient discharge in 2019 , or not having an outpatient appointment scheduled for the year of 2020 .

\section{Data Collection}

To assess the impact of the pandemic on the quality of care indicators for type 1 diabetes, an evaluation of clinical and laboratory parameters of the same cohort of patients was conducted, from the research conducted in 2019, comparing the care provided during the pandemic COVID-19 in the year 2020. The information was collected for one year of follow-up before the last medical appointment in the period, whereas the data were collected using information from the electronic medical records.

In order to identify possible flaws and to reduce bias, the researchers performed simulations and then collected data. The registering procedures were performed using an online form. The sociodemographic characteristics included age, sex, race/ethnicity and scholarity. The comorbidities were evaluated based on records of cardiovascular events, dyslipidemia, arterial hypertension, nephropathy, neuropathy, foot injuries, amputations and psychiatric conditions.

Furthermore, it was obtained information regarding health appointments, including information on the number of outpatient visits (nutrition, nursing and physician), number of teleconsultations performed during the COVID-19 pandemic, body mass index (BMI), and blood pressure. The assessment of neuropathy was performed through the $10 \mathrm{~g}$ Semmes Weinstein monofilament evaluation, or the Ipswich Touch Test, or the vibration sensitivity evaluation records. The assessment of retinopathy was performed according to the last fundus examination or retinography recorded. The information registered was, preferably, extracted from the last appointment (medical, nutrition and nursing) of the patient at the institution.

Finally, laboratory test results were collected, including the measurements of glycated hemoglobin (HbA1c) (measured with NGSP, certified high performance liquid exchange chromatography with MerckHitachi L-9100 Analyzer, Merck, Darmstadt, Germany), creatinine (measured with the traceable Jaffe method), albuminuria (measured in a sample using immunoturbidimetry, Alinity - Abbott Diagnostics, Illinois, USA), lipid profile (total cholesterol, LDL-cholesterol and triglyceride, measured with enzymatic colorimetric methods, Alinity - Abbott Diagnostics, Illinois, USA, and HDL-cholesterol measured with the accelerator selective detergent methodology, Alinity - Abbott Diagnostics, Illinois, USA) and thyroidstimulating hormone (measured with chemiluminescent microparticle immunoassay, Alinity - Abbott 
Diagnostics, Illinois, USA). When there were more tests than recommended by the guidelines [4, 22], the last ones performed were considered.

\section{Quality Of Care Indicators And Outcome Measures}

Quality of Care Indicators and Outcome Measures

The quality of care indicators chosen followed the guidelines of the American Diabetes Association and the Brazilian Diabetes Society $[4,22]$ and included:

1. HbA1c assessment: at least two annual measurements;

2. Retinopathy assessment: annually after five years of diagnosis;

3. Assessment of distal symmetric diabetic neuropathy: annual, through the $10 \mathrm{~g}$ Semmes-Weinstein monofilament or Ipswitch Touch Test or assessment of vibration sensitivity;

4. Evaluation of albuminuria and / or serum creatinine: having at least one measurement in the last year;

5. Lipid profile (total cholesterol, HDL cholesterol, LDL cholesterol, and triglycerides): have a measurement in the last three years;

6. Thyroid-stimulating hormone (TSH): a measure in the last two years;

Furthermore, it was checked if a glycemic target was registered in the patient's online medical record. In daily clinical practice, patients who had a history of ischemic heart disease, records of frequent episodes of hypoglycemia, severe visual impairment, who underwent hemodialysis or peritoneal dialysis, and performed only two or less capillary blood glucose tests per day are considered for a flexible target $(\mathrm{HbA} 1 \mathrm{c} \leq 8.0 \%)$. For all other patients, strict glycemic control was considered adequate (target of HbA1c $\leq 7.0 \%$ ).

The primary outcome was the presence of quality of care indicators (positive or negative) regarding the periods before and during the COVID-19 pandemic in the same cohort of patients. Secondary outcomes include the comparison between the two periods in relation to the presence of all minimum indicators of quality of care in diabetes and of each quality indicator individually, $\mathrm{HbA} 1 \mathrm{c}$ levels, and lipid profile.

\section{Statistical Methods}

Sample size was calculated in the Power and Sample Size Health online version [23] to compare the percentage of individuals who had achieved the goal for quality indicators (HbA1c assessment, retinopathy assessment, distal symmetric diabetic neuropathy assessment, evaluation of albuminuria and / or serum creatinine, lipid profile and TSH) in 2019 but not in 2020, with the percentage of individuals who did not achieve the goal in 2019 but did in 2020 . Considering $80 \%$ power and $5 \%$ significance level, the sample size necessary was at least 81 individuals [24]. 
The data were transcribed from the online platform Google Forms (Alphabet Co., Mountain View, CA) to the Statistical Package for Social Science (SPSS ${ }^{\circledR}$ ) version 22.0 for analysis. Descriptive data are presented as frequency (\%) or mean \pm standard deviation (SD) if the assumption of normal distribution did not seem violated; otherwise, data were reported as median \pm interquartile range (IQR). Normality was defined by the Shapiro-Wilk test. The last results of laboratory tests and the last clinical evaluation available in the medical records were considered for analyses. For the assessment of the primary outcome, a dichotomous outcome (yes/no) was considered for the presence of quality indicators previously defined. The difference between the two periods (prior and during the COVID-19 pandemic) was assessed using the McNemar test for categorical variables and the Wilcoxon test for continuous variables. An alpha value $<0.05$ was used to determine statistical significance.

An exploratory post hoc analysis was performed comparing patients who were included in the study in relation to those excluded for not having a medical appointment scheduled during the pandemic period. The two groups were compared for age, gender, time of diagnosis of diabetes, $\mathrm{HbA} 1 \mathrm{c}$, and number of patients with glycemic control on the target.

\section{Ethical Aspects}

The study was approved by the institution's Research Ethics Committee (No. 20380919800005327). The researchers signed a term of commitment for the use of the institution's data, and the research considered the announced prerogatives in Resolution 466/2012 of the National Health Council. This document follows the STROBE Statement Checklist of items that should be included in reports of observational studies.

\section{Results}

After the initial identification, we obtained 378 medical records from patients with type 1 diabetes mellitus aged 18 years or older, who received care between January 2019 and November 2020. Out of these, we excluded 89 patients according to the exclusion criteria detailed in Figure 1. In total, 289 patients were included in this study, mean age of $40 \pm 12$ years, and 143 (49.5\%) were female. The other demographic and clinical characteristics are summarized in Table 1 . The exploratory post hoc analysis comparing the baseline characteristics of the excluded patients for not having a medical appointment scheduled in the pandemic period, showed that there was no difference between the groups in terms of personal characteristics and glycemic control (data not shown). 
Table 1

Baseline demographic and clinical characteristics of the included participants

\section{Patient characteristic}

Sex male (\%)

Age (years)

Diabetes duration (years)

BMI $\left(\mathrm{kg} / \mathrm{m}^{2}\right)$

Blood pressure $(\mathrm{mmHg})$

Systolic

Diastolic

Chronic complications of diabetes $\mathrm{n}(\%)$

Retinopathy

Nephropathy

Neuropathy

Limb amputation

Bruised feet

Macrovascular complications

Smoker $\mathrm{n}(\%)$

Dyslipidemia

Psychiatric disease

Arterial hypertension

Data is presented as mean \pm SD or $n(\%)$. BMI: body mass index. Macrovascular complications included stroke, ischemic heart disease and peripheral arterial disease.

\section{$\mathrm{n}=\mathbf{2 8 9}$}

$146(50.5)$

$40.7 \pm 12.6$

$22.8 \pm 11.0$

$25.2 \pm 3.9$

$122.9 \pm 16.6$

$78.6 \pm 14.4$
146 (50.5)

51 (18.3)

50 (17.5)

8 (2.8)

24 (8.3)

25 (8.7)

27 (9.4)

40 (14.0)

69 (24.8)

87 (30.1)

During the pandemic, 252 patients had at least one face-to-face nutrition, nursing or physician appointment canceled. Considering the restrictions of conducting those outpatient visits and the Brazilian normative for telehealth in different areas, teleconsultations were introduced in the care of patients, including 98 appointments were performed by physicians, 14 by nursing teams, and 6 by nutrition teams. Furthermore, 10 patients received care by two or more professionals from the multiprofessional team. Only 28 patients did not have any type of assistance - face-to-face nor teleconsultation - in 2020 .

The number of appointments with the multiprofessional team received by the participants during the COVID-19 pandemic was reduced comparing with the period before the pandemic $(p<0.001)$. In 2019, 
considering face-to-face and teleconsultation appointments the median number of physicians appointments performed was 4.0 (3.0-5.0), and during the pandemic (2020), the median was 2.0 (1.03.0). The participants had a median of $1.0(0.0-2.0)$ face-to-face appointments with the nutrition team in 2019, in contrast with $0.0(0.0-1.0)$ in 2020 (face-to-face and teleconsultation appointments).

Furthermore, they had a median of $0.0(0.0-1.0)$ consultation with the nursing team in 2019 (only consultation face-to-face), in contrast with $0.0(0.0-0.0)$ in 2020 considering face-to-face and teleconsultation appointments.

The analysis of the quality of care indicators showed a significant worsening during the COVID-19 pandemic compared to the previous year. There was a reduction in the number of participants who presented all the indicators evaluated, according to the guidelines, in relation to the period prior to the pandemic. Moreover, the reduction in the total number of indicators was significant ( $p<0.001)$ : in 2019, 67 (23.2\%) participants had all the indicators evaluated, whereas in 2020 , during the pandemic, it was only 10 (3.5\%). The number of patients who had each of the quality of care indicators evaluated, in the two periods evaluated, are described in Table 2. There was no difference in mean $\mathrm{HbA} 1 \mathrm{c}$, albuminuria and triglyceride levels in both periods. Considering achievement of glycemic targets, in the year of $201926 \%$ $(n=75)$ of the participants whose HbA1c target could be flexible were on the target, and only $1 \%(n=3)$ of those whose $\mathrm{HbA} 1 \mathrm{c}$ target should be strict were on the target. 
Table 2

Number of patients who presented the quality of care indicators for type 1 diabetes mellitus according to guidelines in the two periods evaluated $(n=289)$.

\begin{tabular}{|c|c|c|c|}
\hline Quality of care indicator & 2019 & 2020 & $\begin{array}{l}\text { P- } \\
\text { value* }\end{array}$ \\
\hline $\begin{array}{l}\text { Assessment of distal simetric diabetic } \\
\text { neuropathy }\end{array}$ & $152(52.8)$ & 119 (41.3) & 0.004 \\
\hline \multirow{2}{*}{$\begin{array}{l}\text { Assessment of albuminuria and / or serum } \\
\text { creatinine }^{a}\end{array}$} & $247(86.1)$ & 206 (71.8) & \multirow{2}{*}{$<001$} \\
\hline & $6.0(3.0-18.0)$ & $6.0(4.0-14.0)$ & \\
\hline Albuminuria value (mg) & \multirow{2}{*}{$0.9(0.7-1.0)$} & \multirow{2}{*}{$1.0(0.8-1.2)$} & \multirow{2}{*}{$\begin{array}{l}0.93 \\
< \\
0.001\end{array}$} \\
\hline Mean creatinine value $(\mathrm{mg} / \mathrm{dl})$ & & & \\
\hline \multirow{4}{*}{ Number of tests assessed } & $263(91.6)$ & $135(47.0)$ & \multirow{4}{*}{$\begin{array}{l}< \\
0.001 \\
<0.001 \\
0.12\end{array}$} \\
\hline & $3(2-3)$ & $1(1-2)$ & \\
\hline & $8.6(7.8-9.8)$ & $8.6(7.6-9.6)$ & \\
\hline & $70.0(62.0-84.0)$ & $70.0(60.0-81.0)$ & \\
\hline \multirow{3}{*}{$\begin{array}{l}\text { Lipid profile }^{\mathrm{a}} \\
\text { Mean total cholesterol(mg/dl) } \\
\text { Mean HDL cholesterol }(\mathrm{mg} / \mathrm{dl})\end{array}$} & $242(84.3)$ & $266(92.7)$ & $<0.001$ \\
\hline & $\begin{array}{l}173.0(151.0- \\
200.0)\end{array}$ & $\begin{array}{l}178.0(152.0- \\
209.0)\end{array}$ & \multirow{2}{*}{$\begin{array}{l}< \\
0.001\end{array}$} \\
\hline & $56.0(46.2-67.0)$ & $53.0(45.0-64.2)$ & \\
\hline $\begin{array}{l}\text { Mean LDL cholesterol }(\mathrm{mg} / \mathrm{dl}) \\
\text { Mean trialvceride }(\mathrm{mg} / \mathrm{dl})\end{array}$ & $\begin{array}{l}101.0(77.3- \\
124.5)\end{array}$ & $\begin{array}{l}104.8(82.5- \\
128.9)\end{array}$ & $<.001$ \\
\hline \multirow{2}{*}{ Mean triglyceride (mg/dl) } & $\begin{array}{l}78.5(58.8- \\
112.0)\end{array}$ & $\begin{array}{l}81.0(60.5- \\
108.0)\end{array}$ & \multirow{2}{*}{$\begin{array}{l}< \\
0.001 \\
0.39\end{array}$} \\
\hline & & & \\
\hline Retinopathy assessment ${ }^{b}$ & $172(63.9)$ & $83(30.9)$ & $<.001$ \\
\hline Thyroid-stimulating hormone assessment & $262(91.6)$ & $256(89.5)$ & 0.080 \\
\hline \multicolumn{4}{|c|}{ 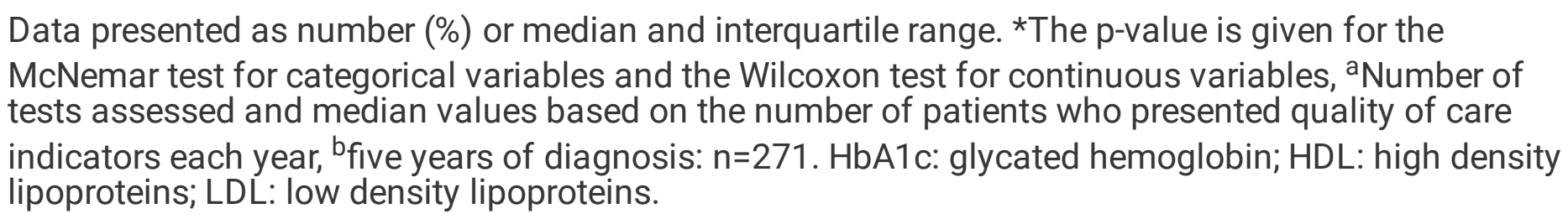 } \\
\hline
\end{tabular}

\section{Discussion}

Our study assessed the impact of the COVID-19 outbreak on quality of care parameters in a cohort of patients with type 1 diabetes in Southern Brazil, according to the indicators proposed by the guidelines. 
The evaluation of the same cohort of patients at two different times, before and during the outbreak, showed a negative impact of the pandemic on the care of type 1 diabetes. The analysis of quality of care indicators revealed a significant worsening during the pandemic compared to the previous year. The number of patients who had all the indicators evaluated was reduced compared to the period before the pandemic, however, there was no difference in participants' glycemic control between the two evaluated periods.

The analysis of the quality of care indicators showed a significant worsening in the frequency of physician, nutrition and nursing appointment, and in the quality parameters when comparing the periods before and during the COVID-19 pandemic. Most evaluated patients did not receive face-to-face care with multidisciplinary teams during the pandemic. These results were expected in the context of the outbreak, since the population was instructed to stay at home and social restrictions were observed in several countries, including the reduction in scheduled appointments $[25,26]$. Individuals with chronic diseases, such as diabetes, have been the most affected by these measures [27]. Moreover, patients who are afraid of going to the hospital made it difficult to maintain a regular assessment routine for diabetes care during the pandemic $[28,37]$. Our study also showed a worsening in the participants' lipid profile, which may be related to worsening eating habits and lower frequency of physical activity during the pandemic $[16,19]$.

Since the beginning of the pandemic, hyperglycemia has been associated with worse outcomes in COVID19 infection, which can generate fear and concern to patients [28-31]. As a result, patients had the preference and were recommended to postpone their clinic visits. The use of multidisciplinary teleconsultations was one of the alternatives adopted to alleviate these assistance difficulties nationally and internationally $[26,32,33]$. Remote technology consultations are increasingly integrated into diabetes care and offer the opportunity to maintain continuity of care in a pandemic setting $[19,31,34]$. However, this approach has drawbacks, especially among patients and healthcare professionals that are not used to it, and also considering the rapid modification that usual care was turned to this new manner. It may exclude disadvantaged and vulnerable patients most in need of support, as disparities in access have been consistently shown, and may disproportionately benefit patients with more resources who already have support for their care, leading to intervention-generated inequalities [35].

The consequences of the social distancing measures, unavailability of health appointments and worsening of the diabetes quality of care have the potential to generate negative impacts on patients with type 1 diabetes. Firstly, it is possible that the worsening of the quality of care parameters results in worse glycemic control, increasing the risk of serious decompensation and complications of the disease. Even before the pandemic, the quality of care for patients with type 1 diabetes in Brazil was already being evaluated, and it was identified the need to improve care for these patients [36].

Our study showed no difference in participants' glycemic control comparing the periods before and during the COVID-19 pandemic. However, the data were analyzed only for the percentage of patients who collected exams in 2020, making it impossible to predict whether the missing data would represent patients with worse glycemic control, because of less assistance, for example, or better glycemic control, 
because they were more at home taking care of themselves, for example. The comparison of patients evaluated in 2020 with those who were excluded from the study because they did not have an appointment scheduled during the pandemic showed no differences. Ghosal et al. designed a mathematical model to demonstrate the possible impact that social isolation and lockdown measures may have on glycemic control in patients with diabetes and predicted a significant increase in $\mathrm{HbA} 1 \mathrm{c}$ and future complications related to diabetes [37]. Furthermore, the lack of follow-up with multidisciplinary teams may result in loss of the patient's bond with the health service, which may not return to the previous care routine after the end of the pandemic. Moreover, these factors directly affect the mental health of these patients, who are at a higher risk of presenting depressive symptoms, diabetes-related emotional distress, eating, and sleeping disorders $[14,38]$. These points justify the importance of maintaining minimum parameters of care during periods of pandemic, and reflect the need to develop and to strengthen alternative care measures in these scenarios.

This study has some limitations, as based on medical records review, it is possible that there are biases related to the recording of information. Besides, the limitations inherent to the design of a cross-sectional study have to be considered, not being possible to attribute causal relationships to the associations found. Another aspect that should be considered is that the use of telehealth appointments was not a routine in our hospital at the beginning of the pandemic, it was gradually introduced from May 2020, when health professionals were trained and a specific telehealth system was developed. Thus, it is possible that, in a system that telehealth appointments are already practiced, the impact of the pandemic on parameters of quality of care in diabetes would be less significant. Even so, it has to be considered that it was the reality experienced in developing countries in 2020 , and health professionals should be alert to the consequences that will be experienced in the coming years.

The COVID-19 pandemic has changed how health assistance is offered to patients with type 1 diabetes. In our study, we found a significant worsening in the minimal quality of care indicators compared to the previous year, which reflects the difficulties faced during the pandemic to offer comprehensive and quality care to these patients. These data show how we are unprepared to provide support for patients with type 1 diabetes in crisis situations and draws attention to the need for quick and alternative strategies to maintain the quality of care in similar situations. Moreover, it is necessary for health professionals to be aware of the possible consequences of the difficulties in health care experienced in the year 2020. Only in this way, we could mitigate the pandemic effects on diabetes care and organize a more efficient system for the future.

\section{Abbreviations}

BMI

Body Mass Index

COVID-19

Coronavirus disease 2019

HbA1c

Page $11 / 16$ 
Glycated Hemoglobin

HDL cholesterol

High Density Lipoprotein

IQR

Interquartile Range

LADA

Latent Autoimmune Diabetes in Adult

LDL cholesterol

Low Density Lipoprotein

MODY

Maturity Onset Diabetes of the Young

NGSP

National Glycohemoglobin Standardization Program

SARS-CoV-2

Severe Acute Respiratory Syndrome

SD

Standard Deviation

SPSS

Statistical Package for Social Science

TSH

Thyroid-stimulating hormone

USA

United States of América

WHO

World Health Organization

\section{Declarations}

\section{Acknowledgements}

Not applicable.

\section{Funding}

This study was funded by the Research Incentive Funding (FIPE) of the Hospital de Clínicas de Porto Alegre (HCPA), Brazilian National Council for Scientific and technology Development (CNPq), and Rio Grande do Sul Research Foundation (FAPERGS), and Graduate Program in Endocrinology, Universidade Federal do Rio Grande do Sul.

\section{Competing interests}

The authors declare that they have no competing interests. 


\section{Data availability}

The dataset used and/or analysed during the current study are available from the corresponding author on reasonable request.

Authors' Contribution LF involved in conceptualization, methodology, data curation, and writing-original draft preparation. JA, BN, and RM, participated in methodology and writing-original draft preparation. GHT participated in supervision and writing-reviewing and editing. BDS involved in conceptualization, supervision, and writing-reviewing and editing.

\section{Ethics approval}

The institution's Ethics and Research Committee approved the study under the Certificate of Presentation for Ethical Appreciation (CAAE) registration No. 20380919800005327.

\section{Consent for publication}

Not applicable.

\section{References}

1. International Diabetes Federation. IDF Diabetes Atlas. 9th ed. Belgium: Brussels; 2019. https://www.diabetesatlas.org. [accessed 05 August 2021].

2. Nathan D, Cleary P, Backlund J, Genuth S, Lachin J, Orchard T, et al. Diabetes Control and Complications Trial Research Group: the effect of intensive treatment of diabetes on the development and progression of long-term complications in insulin dependent diabetes mellitus. The Diabetes Control and Complications Trial Research Group. N Engl J Med. 1993;329(14). https://doi.org/10.1056/NEJM199309303291401.

3. Nathan D, Cleary P, Backlund J, Genuth S, Lachin J, Orchard T, et al. Intensive Diabetes Treatment and Cardiovascular Disease in Patients with Type 1 Diabetes. The Diabetes Control and Complications Trial/Epidemiology of Diabetes Interventions and Complications (DCCT/EDIC) Study Research Group. N Engl J Med. 2005; 353(25). https://doi.org/10.1056/NEJMoa052187.

4. American Diabetes Association. Standards of medical care in diabetes - 2021. Diabetes Care. 2019;42(1):139-47. https://care.diabetesjournals.org/content/42/Supplement_1. [accessed 05 August 2021].

5. Springer D, Dziura J, Tamborlane WV, Steffen AT, Ahern JH, Vincent M, et al. Optimal control of type 1 diabetes mellitus in youth receiving intensive treatment. The Journal of Pediatrics. 2006;149(2):22732. https://doi.org/10.1016/j.jpeds.2006.03.052. PMID: 16887440.

6. Sheehy DF, Quinnell SP, Vegas AJ. Targeting Type 1 Diabetes: Selective Approaches for New Therapies. Biochemistry. 2019;58(4):214-33. https://doi.org/10.1021/acs.biochem.8b01118. 
7. Wiley J, Westbrook M, Long J, Greenfield JR, Day RO, Braithwaite J. Multidisciplinary diabetes team care: the experiences of young adults with Type 1 diabetes. Health expectations: an international journal of public participation in health care health policy. 2015;18(5):1783-96. https://doi.org/10.1111/hex.12170.

8. Perfett R. Comprehensive approach to the management of diabetes: offering improved outcomes for diabetics and the healthcare system. Diabetes Management. 2013;3(6):505-28. https://doi.org/10.2217/dmt.13.51.

9. American Diabetes Association. Strategies for Improving Care. Diabetes Care. 2016;39(1):6-12. https://doi.org/10.2337/dc16-S004.

10. Zheng YY, Ma YT, Zhang JY, Xie X. COVID-19 and the cardiovascular system. Nature Reviews Cardiology. 2020;17(5):259-60. https://doi.org/10.1038/s41569-020-0360-5.

11. Candido DDS, Watts A, Abade L, Kraemer MUG, Pybus OG, Croda J, et al. Routes for COVID-19 importation in Brazil. Journal of Travel Medicine.

12. 2020.;27(3). https://doi.org/10.1093/jtm/taaa042.

13. Brasil. Ministério da Saúde. Painel Coronavírus. 2020, https://covid.saude.gov.br/ [accessed 01 August 2021].

14. Grabia M, Markiewicz-Żukowska R, Puścion-Jakubik A, Bielecka J, Nowakowski P, GromkowskaK囚epka K, et al. The Nutritional and Health Effects of the COVID-19 Pandemic on Patients with Diabetes Mellitus. Nutrients. 2020;12(10):3013. https://doi.org/10.3390/nu12103013.

15. Alessi J, de Oliveira GB, Franco DW, do Amaral BB, Becker AS, Knijnik CP, et al. Mental health in the era of COVID-19: prevalence of psychiatric disorders in a cohort of patients with type 1 and type 2 diabetes during the social distancing. Diabetology Metabolic Syndrome. 2020;12:76. https://doi.org/10.1186/s13098-020-00584-6.

16. Ruiz-Roso MB, Knott-Torcal C, Matilla-Escalante DC, Garcimartín A, Sampedro-Nuñez MA, Dávalos A, et al. COVID-19 Lockdown and Changes of the Dietary Pattern and Physical Activity Habits in a Cohort of Patients with Type 2 Diabetes Mellitus. Nutrients. 2020;12(8):2327. https://doi.org/10.3390/nu12082327.

17. Alessi J, de Oliveira GB, Feiden G, Schaan BD, Telo GH. Caring for caregivers: the impact of the ] COVID-19 pandemic on those responsible for children and adolescents with type 1 diabetes. Sci Rep. 2021;11(1):6812. https://doi.org/10.1038/s41598-021-85874-3. PMID: 33762633; PMCID: PMC7991637.

18. Coma E, Mora N, Méndez L, Benítez M, Hermosilla E, Fàbregas $M$, et al. Primary care in the time of COVID-19: monitoring the effect of the pandemic and the lockdown measures on 34 quality of care indicators calculated for 288 primary care practices covering about 6 million people in Catalonia. BMC Family Practice. 2020;21(1):208. https://doi.org/10.1186/s12875-020-01278-8.

19. Verhoeven V, Tsakitzidis G, Philips H, Van Royen P. Impact of the COVID-19 pandemic on the core functions of primary care: will the cure be worse than the disease? A qualitative interview study in Flemish GPs. BMJ Open. 2020;10(6):e039674. https://doi.org/10.1136/bmjopen-2020-039674. 
20. Alessi J, de Oliveira GB, Franco DW, et al. Telehealth strategy to mitigate the negative psychological impact of the COVID-19 pandemic on type 2 diabetes: A randomized controlled trial. Acta Diabetol. 2021;58:899-909. https://doi.org/10.1007/s00592-021-01690-1.

21. Informe epidemiológico - COVID 19. Secretaria Estadual de Saúde do Rio Grande do Sul - SES RS, https://coronavirus.rs.gov.br/informe-epidemiologico [accessed 18 March 2021].

22. Transparência COVID-19. Painel Mobilidade e Distanciamento. Prefeitura de Porto Alegre PROCEMPA, https://infografico-covid.procempa.com.br/distanciamento-social [accessed 18 March 2021].

23. Sociedade Brasileira de Diabetes. Diretrizes da Sociedade Brasileira de Diabetes 2019-2020. São Paulo: Editora Clannad, 2020, http://www.saude.ba.gov.br/wp-content/uploads/2020/02/DiretrizesSociedade-Brasileira-de-Diabetes-2019-2020.pdf [accessed 05 August 2021].

24. Borges RB, Azambuja GS, Mancuso ACB, Leotti VB, Hirakata VN, Camey SA, et al. PSS. Health: Power and Sample Size for Health Researchers via Shiny. R package. 2021, https://CRAN.Rproject.org/package=PSS. Health [accessed 05 August 2021].

25. Foppa L, Alessi J, Monteiro LERS, Borger RP, Hadata TF, David JS, et al. Qualidade do atendimento aos pacientes com diabetes mellitus tipo 1 em hospital universitário do Sul do Brasil. In: 40 Semana Científica do Hospital de Clínicas de Porto Alegre. Clinical \& Biomedical Research - 2020. ISSN Eletrônico: 2357-9730, https://www.hcpa.edu.br/downloads/anais40asc-final.pdf [accesed 05 August 2021].

26. Capaldo B, Annuzzi G, Creanza A, Giglio C, De Angelis R, Lupoli R, et al. Blood Glucose Control During Lockdown for COVID-19: CGM Metrics in Italian Adults With Type 1 Diabetes. Diabetes Care. 2020;43(8):e88-9. https://doi.org/10.2337/dc20-1127.

27. Wosik J, Fudim M, Cameron B, Gellad ZF, Cho A, Phinney D, et al. Telehealth transformation: COVID19 and the rise of virtual care. J Am Med Inform Assoc. 2020;27(6):957-62. https://doi.org/10.1093/jamia/ocaa067.

28. Bonora BM, Boscari F, Avogaro A, Bruttomesso D, Fadini GP. Glycaemic Control Among People with Type 1 Diabetes During Lockdown for the SARS-CoV-2 Outbreak in Italy. Diabetes Ther. 2020;11(6):1-11. https://doi.org/10.1007/s13300-020-00829-7.

29. Yaribeygi H, Sathyapalan T, Jamialahmadi T, Sahebkar A. The Impact of Diabetes Mellitus in COVID19: A Mechanistic Review of Molecular Interactions. Journal of Diabetes Research v2020 Article ID. 2020;5436832:9 pages. https://doi.org/10.1155/2020/5436832.

30. Bhatti R, Khamis AH, Khatib S, Shiraz S, Matfin G. Clinical Characteristics and Outcomes of Patients With Diabetes Admitted for COVID-19 Treatment in Dubai: Single-Centre Cross-Sectional Study. JMIR Public Health Surveill. 2020;6(4):e22471. https://doi.org/10.2196/22471.

31. Ebekozien OA, Noor N, Gallagher MP, Alonso GT. Type 1 Diabetes and COVID-19.

32. Preliminary Findings From a Multicenter Surveillance Study in the U.S. Diabetes Care. 2020;43:e835. https://doi.org/10.2337/dc20-1088. 
33. Bezerra ACV, da Silva CEM, Soares FRG, da Silva JAM. Ciência e Saúde coletiva. 2020;25(1):241121. https://doi.org/10.1590/1413-81232020256.1.10792020.

34. Brasil. Portaria $n^{\circ}$ 467, de 20 de março de 2020, https://www.in.gov.br/en/web/dou/-/portaria-n-467de-20-de-marco-de-2020-249312996 [accessed 07 January 2021].

35. Blandford A, Wesson J, Amalberti R, AlHazme R, Allwihan R. Opportunities and challenges for telehealth within, and beyond, a pandemic. Lancet Global Health. 2020;8(11):e1364-5. https://doi.org/10.1016/S2214-109X(20)30362-4.

36. Quinn LM, Davies MJ, Hadjiconstantinou M. Virtual Consultations and the Role of Technology During the COVID-19 Pandemic for People With Type 2 Diabetes: The UK Perspective. Journal of Medical Internet Research. 2020;22(8):e21609. https://doi.org/10.2196/21609.

37. Veinot TC, Mitchell H, Ancker JS. Good intentions are not enough: how informatics interventions can worsen inequality. J Am Med Inform Assoc. 2018;25(8):1080-8. https://doi.org/10.1093/jamia/ocy052.

38. Gomes MB, Coral M, Cobas RA, Dib SA, Canini LH, Nery M, et al. Prevalence of adults with type 1 diabetes who meet the goals of care in daily clinical practice: A nationwide multicenter study in Brazil. Diabetes Res Clin Pract. 2012;97(1):63-70. https://doi.org/10.1016/j.diabres.2012.02.008.

39. Ghosal S, Sinha B, Majumder M, Misra A. Estimation of effects of nationwide lockdown for containing coronavirus infection on worsening of glycosylated haemoglobin and increase in diabetes-related complications: A simulation model using multivariate regression analysis. Diabetes Metabolic Syndrome. 2020;14(4):319-23. https://doi.org/10.1016/j.sds.2020.03.014.

40. Telo GH, Cureau FV, Lopes CS, Schaan BD. Common mental disorders in adolescents with and without type 1 diabetes: Reported occurrence from a countrywide survey. Diabetes Res Clin Pract. 2018;135:192-198. https://doi.org/10.1016/j.diabres.2017.10.027. Epub 2017 Nov 16. PMID: 29155124.

\section{Figures}

\section{Figure 1}

Flow diagram of exclusion criteria 